\title{
16th Conference on Solid State Analysis
}

\author{
Gernot Friedbacher
}

Published online: 13 March 2012

(C) Springer-Verlag 2012

The conference series on Solid State Analysis (Festkörperanalytik) is devoted to the presentation of analyticalmethodological developments and scientific-technological problem-solving strategies within the framework of the investigation of solids. The focus of the conference is the exchange of information between analysts, material scientists, solid state physicists, and technologists. The conference takes place every two years alternately in Vienna, Austria and Chemnitz, Germany. The 16th Conference on Solid State Analysis, which was held at the Vienna University of Technology, July 4-6, 2011, under the auspices of the Institute of Chemical Technologies and Analytics, Vienna University of Technology, the Institute of Chemistry and the Institute of Physics, Chemnitz University of Technology, the Austrian Society for Analytical Chemistry (ASAC), the Chemikerausschuss of the Verein Deutscher Eisenhüttenleute, the Deutsche Gesellschaft für Materialkunde, the Fachgruppen Analytische Chemie and Festkörperchemie und Materialforschung of the German Chemical Society (GDCh), the Deutscher Arbeitskreis für Angewandte Spektroskopie, the GDMB Gesellschaft für Bergbau, Metallurgie, Rohstoff- und Umwelttechnik, the Deutscher Verband für Materialforschung und -prüfung, the Deutsche

Published in the special paper collection Solid State Analysis (FKA 16) with guest editor G. Friedbacher.

G. Friedbacher $(\bowtie)$

Institute of Chemical Technologies and Analytics,

Division of Instrumental Analytical Chemistry,

Vienna University of Technology,

Getreidemarkt 9/164-IAC,

1060 Vienna, Austria

e-mail: gernot.friedbacher@tuwien.ac.at
Vakuumgesellschaft e.V. (DVG), and the Fachverband Mikrosonden of the German Physical Society, was attended by about 200 scientists mostly from Germany and Austria, but also including some guests from Belarus, Czech Republic, Romania, Switzerland, and the USA emphasizing its success as a platform bringing together participants from academia and industry for scientific exchange in all fields of solid state analysis.

The main topics of the conference were elemental and compound analysis, micro- and nanoanalysis, surface and interface analysis, trace analysis, structural analysis, chemical reactions in solids and at solid surfaces, dynamic behavior of solids, new instrumental developments, as well as analytics for material development and production including metals, semiconductors, ceramics, glass, polymers, biomaterials, layered materials, nanostructured materials, quality assurance, and chemometrical aspects. These topics were covered by 9 plenary lectures and 90 contributed papers. Plenary lectures were given by L. Eng, TU Dresden, Germany (Multiferroics: wide-bandgap semiconductors with challenging applications), F. Friedel, ThyssenKrupp AG, Duisburg, Germany (Application of materials characterization for establishing models for simulation of steels), G. Frischat, TU Clausthal, Germany (Analytical methods for the measurement of transport processes in glasses), I. Gornushkin, BAM Berlin, Germany (Laser-induced breakdown spectroscopy (LIBS) and Raman spectroscopy for materials analysis), P. Hinterdorfer, Johannes Kepler University, Linz, Austria (Single molecule spectroscopy and microscopy in biology and medicine), R. Kaindl, Joanneum Research, Weiz, Austria (Raman spectroscopy of materials - thin layers and cordierite), A. Knop-Gericke, Fritz Haber Institut Berlin, Germany (Investigation of solid-gas interfaces with photoelectron spectroscopy under reaction 
conditions), J. Thomas, IFW Dresden, Germany (Analysis of thin functional layers with electron diffraction), C. Vogt, University of Hannover, Germany (Trace analysis in solids).

The scientific program was accompanied by a commercial exhibition of analytical instruments, which gave the opportunity to 24 companies to inform the participants about new developments on the market. Short oral presentations by the companies were particularly welcomed both by the representatives and the audience.

The social program included a welcome reception on Sunday evening and a traditional Viennese "Heurigen" evening in Wien-Nussdorf at the end of the conference where the attendees continued scientific and personal discussions in a very charming atmosphere with Viennese wine and a typical Viennese "Heurigen" buffet. Apart from this social program, the participants had the opportunity to enjoy the lovely atmosphere of the city of Vienna with its enormous cultural program.

Successful organization of the conference, particularly the scientific program, was based on the activities of the members of the scientific committee consisting of G. Friedbacher (Wien, chair), M. Hietschold (Chemnitz, co-chair,) J. Broeckaert (Hamburg), R. Denecke (Leipzig), H.-J. Engelmann (Dresden), W.A. Goedel (Chemnitz), D. Günther (Zürich), R. Holze (Chemnitz), M. Kopnarski (Kaiserslautern), H. S. Leipner (Halle), G. Marx (Chemnitz), J. Mayer (Aachen), K.-H. Müller (Soest), H. Nickel (Jülich), K. Niemax (Dortmund), H. Oechsner (Kaiserslautern), P. Portella (Berlin),
V. Thien (Mülheim), K. Wetzig (Dresden), and Ch. Ziegler (Kaiserslautern).

The organizers of this conference are also grateful to the former members of the scientific committee, M. Aeschlimann (Kaiserslautern), R. Szargan (Leipzig), and H. Vetters (Bremen), for contributing to and developing this conference series. The commitment of all members of the scientific committee is an important basis for continued success of this conference series.

Finally, the organizers would like to thank the Austrian Ministry for Science and Research as well as all commercial sponsors for financial support of the conference. Furthermore, help from numerous volunteers at the Institute of Chemical Technologies and Analytics, technical staff at the Vienna University of Technology, and expert assistance from the staff at Springer-Verlag are gratefully acknowledged.

The next conference on Solid State Analysis is scheduled to take place in Chemnitz in 2013.

Gernot Friedbacher is Associate Professor of Analytical Chemistry at the Vienna University of Technology. His research activities focus on the investigation of surfaces and surface processes with scanning probe microscopy and electron probe $\mathrm{x}$-ray microanalysis. He has published over 120 research articles, reviews, and book chapters, and he is editor of the 2nd edition of Surface and Thin Film Analysis published in 2011. 